\title{
PENDEKATAN FLOOR TIME UNTUK MENINGKATKAN EFEKTIVITAS PEMBELAJARAN PAI BAGI PENGIDAP SINDROM ASPERGER
}

\author{
ARDILLA NANDA ROKHMAN \\ Institut PTIQ Jakarta \\ Nandarokhman@gmail.com
}

\begin{abstract}
ABSTRAK
Hasil yang ditemukan dalam tesis ini adalah Pendekatan Floor time membuat interaksi pembelajaran memiliki makna secara emosional sehingga anak mampu menguasai kemampuan yang penting dalam perkembangannya. Dengan pendekatan floor time anak autis dapat berkomunikasi dan berbahasa secara baik, sehingga mereka bisa berinteraksi dengan lingkungannya..Floor Time menciptakan interaksi dan komunikasi yang berkesinambungan, sehingga anak autis bisa berkomunikasi dengan baik. Pendekatan Floor Time memiliki landasan pada enam tahap perkembangan yang telah dicapai anak terutama relasi interaktif yang paling mendukung perkembangannya. Dibandingkan dengan pendekatan lain, pendekatan Floor Time sangat memberikan perhatian yang khusus dan mendalam, serta sangat mendukung efektifitas pembelajaran PAI bagi guru dan anak autis. Floor Time sangat membantu komunikasi dua arah antara guru dan anak autis yang mana sangat dibutuhkan oleh anak autis agar efektif dalam pembelajaran khususnya PAI. Dibandingkan dengan pendekatan lain Floor Time lebih memberikan dorongan untuk mengungkapkan dan menggunakan perasaan dan ide-ide. Dan hal ini membuat anak autis lebih percaya diri. Floor Time sangat membantu anak autis berpikir yang logis. Penelitian ini menggunakan metode deskriptif kualitatif dengan sumber data primer. Pendekatan yang digunakan dalam Tesis ini adalah pendekatan Floor Time. Berdasarkan kajian yang dilakukan dapat dipahami bahwa . Pendekatan Floor time membuat interaksi pembelajaran memiliki makna secara emosional sehingga anak mampu menguasai kemampuan yang penting dalam perkembangannya. Dengan pendekatan floor time anak autis dapat berkomunikasi dan berbahasa secara baik, sehingga mereka bisa berinteraksi dengan lingkungannya.
\end{abstract}

Kata kunci: Floor Time, Efektivitas pembelajaran PAI dan Pengidap Sindrom Asperger

\begin{abstract}
The results found in this thesis are the Floor time Approach to make learning interactions have emotional meaning so that children are able to master abilities that are important in their development. With the floor time approach, autistic children can communicate and speak well, so they can interact with their environment. Fluor Time creates continuous interaction and communication, so that autistic children can communicate well. The Floor Time Approach has a foundation on the six stages of development that children have achieved, especially interactive relationships that most support their development. Compared to other approaches, the Floor Time approach gives special and in-depth attention, and strongly supports the effectiveness of
\end{abstract}


PAI learning for teachers and children with autism. Floor Time really helps two-way communication between teachers and children with autism which is needed by children with autism to be effective in learning, especially PAI. Compared to other approaches Floor Time gives more impetus to express and use feelings and ideas. And this makes autistic children more confident. Floor Time really helps autistic children think logically. This research uses descriptive qualitative method with primary data sources. The approach used in this thesis is the Floor Time approach. Based on the studies conducted, it can be understood that. Floor time approach makes learning interactions have emotional meaning so that children are able to master abilities that are important in their development. With the floor time approach, autistic children can communicate and speak well, so they can interact with their environment.

Keywords: Floor Time, the effectiveness of PAI learning and people with Asperger's Syndrome 


\section{A. PENDAHULUAN}

Anak berkebutuhan khusus adalah anak yang dalam proses pertumbuhan/perkembangannya secara signifikan mengalami kelainan/penyimpangan (fisik, mental, intelektual, sosial, emosi, emosional) dibandingkan anak-anak lain seusianya sehingga mereka memerlukan pelayanan pendidikan secara khusus. ${ }^{1}$ Anak berkebutuhan khusus memiliki karakteristik yang berbeda-beda berdasarkan kelainan yang mereka miliki, salah satunya adalah anak autis. Autisme merupakan suatu gangguan perkembangan, gangguan pemahaman atau gangguan fungsi otak yang bersifat pervasive, dan bukan suatu bentuk penyakit mental. Gangguan perkembangan fungsi otak yang bersifat pervasive (inco) yaitu meliputi gangguan kognitif (kemampuan pengetahuan), bahasa, perilaku, komunikasi, dan gangguan interaksi social. Autisme atau juga biasa disebut ASD (Autistic Spectrum Disorder) merupakan gangguan perkembangan fungsi otak yang kompleks dan sangat bervariasi (Spectrum). Gangguan ini meliputi cara berkomunikasi, berinteraksi social dan kemampuan berimajinasi. $^{2}$

Lembaga kesehatan Synopsis of Psychiatry menyatakan bahwa setiap tahun di seluruh dunia, kasus autisme mengalami peningkatan. Awal tahun 1990-an, kasus autisme masih berkisar pada perbandingan 1:2.000 kelahiran. Di Amerika Serikat, menurut Sutism Research Institute pada tahun 2000 meningkat menjadi 1 dari 150 anak memiliki kecenderungan menderita autisme. Prevalensi penyandang autisme di seluruh dunia menurut data UNESCO pada tahun 2011 yaitu 35 juta orang penyandang autisme di dunia adalah 6 di antara 1000 orang mengidap autis ${ }^{3}$. Center for Disease Control (CDC) melaporkan data prevalensi autis dari tahun 2010-2014 mengalami peningkatan. Di tahun 2014, CDC memperkirakan bahwa 1 dari 68 anak (atau 14,7 per 1.000 anak usia delapan tahun) di beberapa komunitas di Amerika Serikat telah diidentifikasi dengan ASD. Perkiraan baru ini sekitar 30\% lebih tinggi dari perkiraan sebelumnya. Dilaporkan pada tahun 2012 yaitu 1 dari 88 anak (11,3 per 1.000 anak usia delapan tahun) yang diidentifikasi dengan ASD. Di Amerika kelainan autisme 5 kali lebih sering ditemukan pada anak lakilaki dibandingkan anak perempuan yaitu 1 di

\footnotetext{
${ }^{1}$ Saihu, "Komunikasi Pendidik Terhadap Anak Berkebutuhan Khusus di Sekolah Khusus AsySyifa Larangan", Andragogi: Jurnal Pendidikan Islam, VOL 1, No. 3 (2019): 418-440.

2 Amalia Risqi Puspitaningsih, Vidya pratiwi, "Pendekatan Pembelajaran Anak Autis," Jurnal Riset Pendidikan Dasar, Vol 01, No. 1. (2013), 79.

${ }^{3}$ City Directory, "Angka Kejadian Autis 2011" http://vivirizkiamelia.blogspot.com/2.htm. Diakses pada 5 September 2019
} 
antara 42 anak laki-laki dan 1 di antara 189 anak perempuan. Lebih sering banyak diderita anak berkulit putih dibandingkan berkulit hitam. ${ }^{4}$ Di Indonesia, pada tahun 2013 diperkirakan terdapat lebih dari 112.000 anak yang menderita autisme dalam usia 5-19 tahun. ${ }^{5}$ Saat ini belum ada data khusus terkait angka kejadian autisme, namun Kementerian Kesehatan (Kemenkes) menyebutkan jumlah anak autis cukup tinggi di Indonesia. ${ }^{5}$

Orang dengan Autisme Spectrum Disorder (ASD) dapat menghambat mereka dalam pendidikan dan berhubungan sosial. Sementara beberapa individu dengan ASD dan gangguan perkembangan lain memiliki berbagai tingkat kemampuan kemandirian dan hidup produktif dengan berbagai tingkat dukungan, sebagian sangat bergantung, memerlukan perawatan seumur hidup dan dukungan ${ }^{6}$. Belum ada satu terapi yang dapat menyembuhkan autism secara cepat. Penanganan terbaik adalah dengan diagnosa akurat, pendidikan tepat dan dukungan kuat dari keluarga, khususnya orang tua. Peningkatan prevalensi ASD dan gangguan perkembangan lainnya, pada orang yang tinggal di negara berpenghasilan rendah dan menengah. ${ }^{6}$

Hal yang mendasar dari anak autis yaitu kesulitan dalam memahami apa yang mereka lihat, dengar dan mereka rasakan. Sehingga dalam proses belajar mengajar seorang pendidik dituntut untuk bisa memberikan pemahaman terhadap anak autis. Karena anak autis memiliki kekurangan dari segi komunikasi serta bersosialisasi. Dalam melakukan interaksi dengan seseorang. Hal yang harus dipahami pertama yaitu dari bahasa mereka. Karena bahasa merupakan komunikasi manusia dalam mengadakan hubungan dengan sesama. ${ }^{7}$

Dewasa ini masih banyak guru dan orang tua yang belum mengenali dan paham mengenai gejala autisme dan cara penangannya pada anak autism, khususnya dalam pembelajaran yang berkaitan dengan keagamaan. Hal lain yang memperberat penanganan autisme ini adalah pandangan negatif masyarakat terhadap penyandang autisme masih kuat, terutama di luar Jakarta. Anak autisme sering dianggap sebagai anak dengan gangguan jiwa. Bahkan, banyak orangtua yang malu dan menyembunyikan anaknya. Ketidaksiapan orangtua menerima kondisi anak apa

${ }^{4}$ Center for Disease Control and Prevention,."CDC Estimates 1 in 68 Children has been Identified with Autism Spectrum Disorder"http://www.cdc.gov/media/releases/2014/p.html._Diakses pada 5 September 2019.

5 Hazliansyah, "112.000 Anak Indonesia Diperkirakan Menyandang Autisme" http://www.republika.co.id/.Diakses pada 5 September 2019.

${ }^{6}$ World Health Organization, "Autism Spectrum Disorder \& Others Developmental Disorder from Raising Awareness to Building Capacity"http://www.who.int/iris/bitstream ${ }_{\text {L }}$ Diakses pada 5 September 2019.

7 Amalia Risqi Puspitaningsih, Vidya pratiwi, "Pendekatan Pembelajaran Anak Autis,"Jurnal Riset Pendidikan Dasar, Vol. 01. No. 1. (2013), 80. 
adanya itu terjadi pada semua kelompok masyarakat, termasuk mereka yang berpendidikan dan berpenghasilan tinggi. Terlebih lagi masih kurangnya penanganan anak autis di bidang spiritual menjadi masalah yang masih sulit ditangani. Hal ini akan memperberat penanganan pengidap autisme mencapai perilaku yang baik terlebih lagi dalam hal kemandiriannya. ${ }^{8}$

Pendidikan memegang peranan yang sangat penting dalam kehidupan sosial suatu negara untuk menjamin kelangsungan hidup berbangsa dan bernegara.Karena bagaimanapun juga, pendidikan merupakan wahana untuk mencetak Sumber Daya Manusia (SDM) yang berkualitas 9 . Dengan demikian, dibutuhkan lembaga-lembaga yang mampu mewujudkan tujuan pendidikan nasional sebagaimana tercantum dalam Undang-Undang Sistem Pendidikan Nasional No 20 tahun 2003 : Tujuan Pendidikan nasional yaitu mengembangkan potensi peserta didik agar menjadi manusia yang beriman dan bertakwa kepada Tuhan Yang Maha Esa, berakhlaq mulia, sehat, berilmu, cakap, kreatif, mandiri dan menjadi warga negara yang demokratis dan bertanggung jawab.

Setiap anak berhak untuk mendapatkan pendidikan yang layak tanpa memandang latar belakang, agama, suku bangsa, ekonomi dan status sosialnya. Hal ini didasarkan pada Undang-Undang Republik Indonesia No 20 tahun 2003 tentang Sistem Pendidikan Nasional yang memberikan warnalain dalam penyediaan pendidikan bagi anak berkelaianan ${ }^{10}$. Pada penjelasan pasal 15 tentang pendidikan khusus disebutkan bahwa : Pendidikan khusus merupakan penyelenggaraan pendidikan untuk peserta didik yang berkelaianan atau peserta didik yang memiliki kecerdasan luar biasa yang diselenggarakan secara inklusif atau berupa satuan pendidikan khusus pada tingkat pendidikan dasar, menengah dan tinggi. Pasal inilah yang memungkinkan terobosan bentuk pelayanan pendidikan bagi anak berkebutuhan khusus termasuk autis, berupa penyelenggaraan pendidikan khusus dengan pendekatan yang tepat agar pembelajaran untuk anak autis berjalan dengan efektif, khususnya dalam pencapaian akhlak mulia melalui materi pelajaran PAI.

\section{B. METODE}

Salah satu pendekatan yang baik untuk anak berpengidap Sindrom Asperger dalam berkomunikasi yaitu pendekatan The Developmental Individual Difference Relationship-Based (DIR) atau lebih dikenal dengan pendekatan floor time. Floor time, arti

8 YPAC, Buku Pedoman Penanganan dan Pendidikan Autisme, (Jakarta: Pryzaldi Institute, 2019), 3. 2006), 2.

${ }^{8}$ E. Mulyasa, Menciptakan Pembelajaran Kreatif dan Menyenangkan (Bandung: Remaja Rosdakarya,

10 Republik Indonesia, Undang-Undang Dasar Republik Indonesia No 20 tahun 2003 Sistem Pendidikan Nasional, 76. 
harfiahnya ialah waktu bermain di lantai, namun prakteknya bermain tidak hanya di lantai saja tetapi bisa di mana saja. Pada Floor time, guru, orang tua ataupun siapa saja yang melakukan floor time dengan anak, dituntut ramai/aktif memberi komentar, memancing komunikasi (membuka \& menutup lingkaran komunikasi). Komunikasi di sini bisa sekedar gesture. Pendekatan floor time sangat erat dan tidak bisa lepas dengan terapi Sensory Integration. Untuk anak yang speech delay, yang digarap bukan speechnya langsung, namun sensory yang berkaitan dengan oral motor. ${ }^{11}$

Floor Time merupakan pendekatan yang berbasis perkembangan emosi dan intelegnsi $(\mathrm{D}=$ developmenental), perbedaan profil sensory setiap orang (I=Individual difference) dan relasi personal ( $R=$ relationship based). Pendekatan ini dimulai dengan suasana yang menyenangkan dalam menciptakan interaksi dan komunikasi yang berkesinambungan, sehingga anak autis bisa berkomunikasi dengan baik. Pendekatan DIR memiliki landasan pada enam tahap perkembangan yang telah dicapai anak terutama relasi interaktif yang paling mendukung perkembangannya. Salah satu komponen yang ada pada pendekatan DIR yaitu pendekatan Floor time. Pendekatan Floor time yaitu berfokus dalam penciptaan interaksi pembelajaran yang bermakna secara emosional sehingga anak belajar menguasai kemampuan yang penting dalam perkembangannya. Dengan pendekatan floor time anak autis dapat berkomunikasi dan berbahasa secara baik, sehingga mereka bisa berinteraksi dengan lingkungannya. Seseorang dapat dilihat dari segi berbahasanya, karena semakin terampil dalam berbahasa semakin baik interaksi yang terjalin dengan lingkungnya. Keterampilan tersebut hanya bisa diperoleh dari praktek dan latihan. Penguasaan bahasa baik bahasa ekspresif maupun bahasa reseptif penting bagi anak autis agar dapat berkomunikasi, berinteraksi, menyampaikan ide/pikirannya, dan menyesuaikan dengan lingkungannya. Dengan memiliki komunikasi yang baik, anak autis dapat mengikuti pembelajaran di kelas dengan baik pula. Namun salah satu kekurangan anak autis dalam hal berbahasa dan berkomunikasi maka anak autis pun mengalami kesukaran dalammemahami arti kata-kata serta penggunaan bahasa yang sesuai konteksnya. ${ }^{12}$

Dr. Greenspan menyatakan bahwa: "Floor time, a systematic way of working with a child to help him climb the developmental ladder, ......" Floor time merupakan suatu cara sistematis bekerja dengan peserta didik untuk membantunya melalui tahapan perkembangan, dengan harapan dapat membentuk emosi yang sehat, sosial dan intelektual. Floor time seperti interaksi biasa dan bermain secara spontan dan menyenangkan. Pendidik, orang tua atau terapis hanya mengikuti keinginan peserta

${ }_{11}$ Sistem Cara Bermain Floor Time http:/Www.puterakembara.org Diakses Tangal 6 Oktober 2019.

${ }_{12}$ Amalia Risqi Puspitaningsih, Vidya pratiwi, "Pendekatan Pembelajaran Anak Autis," Jurnal Riset Pendidikan Dasar, Vol, 01. No. 1. (2013): 80. 
didik dan bermain apapun yang menjadi minat, tetapi juga mendorong anak untuk mau berinteraksi dengan pendidik, orang tua atau terapis. ${ }^{13}$

Pengertian tentang floor time sebagai 'mengikuti anak bermain sesuai kemauan dia \& mengarahkan lebih lanjut cukup tepat. Floor time jika di dalam dunia pendidikan anak mirip dengan dengan Cara Belajar Siswa Aktif (Active learning) yaitu yang diutamakan adalah memancing \& mengembangakan inisiatif, daya pikir sendiri \& kemandirian dalam mempelajari sesuatu. Pendekatan ini diharapkan dapat menjadi tambahan alternative atas pendekatan perilaku (behavioral approach) yang sudah lebih popular di Indonesia. Secara umum memang sering disebut floor time saja. Walaupun DIR itu lebih luas dari sekedar ber floor time. Secara harfiah memang floor time berarti get down on the floor and play with your child, namun maknanya bukan eksplisit sebatas bermain di lantai dengan anak. Melainkan mengikuti petunjuk anak (Follows Child Lead). Sehingga kita bisa memahami setiap tindakan dan pikirannya agar kita bisa menuntunnya meniti tahapan perkembangan anak yang seharusnya. ${ }^{13}$

Menurut Theo Peeters, Sindrom asperger (autisme) merupakan suatu gangguan perkembangan, gangguan pemahaman atau gangguan pervaise dan bukan bentuk penyakit mental ${ }^{14}$. Pengertian senada juga ditulis oleh James Le Fanu, yaitu,"Syndrom asperger (autism) merupakan sebuah gangguan perkembangan yang mempengaruhi cara seorang anak dalam memproses informasi dari panca indera mereka" ${ }^{15}$. Sindrom Asperger adalah gangguan perkembangan yang membuat penderitanya sangat sulit untuk berinteraksi dengan orang lain. Anak Anda mungkin merasa sulit untuk berteman karena mereka merasa canggung. Orang dengan sindrom Asperger memiliki beberapa ciri autisme. Sebagai contoh, mereka mungkin memiliki keterampilan sosial yang buruk, lebih menyukai rutinitas, dan tidak menyukai perubahan. Namun tidak seperti anak-anak dengan autis, anak-anak dengan sindrom asperger biasanya mulai berbicara sebelum usia 2 tahun, yaitu usia dimana kemampuan bicara anak mulai berkembang. ${ }^{16}$

Sindrom Asperger merupakan kondisi seumur hidup, tetapi gejala cenderung membaik seiring berlalunya waktu. Orang dewasa dengan kondisi ini bisa belajar untuk memahami kelebihan dan kekurangan mereka sendiri. Dan mereka dapat meningkatkan keterampilan sosial mereka. Sindrom Asperger dan autisme termasuk dalam kelompok gangguan yang disebut gangguan perkembangan pervasif (pervasive

${ }^{13}$ Stanley Greenspan I, The Child with Special Needs,( USA: Perseus Books, 1998), 5.

${ }^{13}$ Theo Peeters, Austisme Hubungan Pengetahuan Teroritis dan Intervensi Pendidikan bagi Penyandang Autis. 14.

${ }^{14}$ James Le Fanu, Deteksi Dini Masalah-Masalah Psikologi Anak (Yogyakarta: Kutubuna, 2009), 320.

15 Sindrom Asperger Www.Dokita.co.id. Diakses tanggal 9 November 2018.

${ }^{16}$ Theo Peeters, Austisme Hubungan Pengetahuan Teroritis dan Intervensi Pendidikan bagi Penyandang Autis. 36. 
developmental disorders). Menurut definisi, penyandang SA mempunyai IQ.normal dan banyak dari mereka (walaupun tidak semua) memperlihatkan pengecualian dalam keterampilan atau bakat di bidang tertentu. Karena mereka memiliki fungsionalitas tingkat tinggi serta bersifat naif, maka mereka dianggap eksentrik, aneh dan mudah dijadikan bahan untuk ejekan dan sering dipaksa temanya untuk berbuat sesuatu yang tidak senonoh. Walaupun perkembangan bahasa mereka kelihatannya normal, namun penyandang SA sering tidak pragmatis dan prosodi. Perbendaharaan kata-kata mereka kadang sangat kaya dan beberapa anak sering dianggap sebagai 'profesor kecil'. Namun mereka dapat menguasai literatur tapi sulit menggunakan bahasa dalam konteks sosial. ${ }^{17}$

Sindrom Asperger adalah gangguan neurologis atau saraf yang tergolong ke dalam gangguan spektrum autisme. Gangguan spektrum autisme (autism spectrum disorder) atau yang lebih dikenal dengan penyakit autisme merupakan gangguan pada sistem saraf yang memengaruhi kemampuan seseorang dalam berkomunikasi dan berinteraksi dengan orang lain. Sindrom Asperger memiliki gejala-gejala yang tidak terlalu berat dibandingkan dengan jenis penyakit autisme lainnya.

Sindrom ini ditemukan oleh Hans Asperger, seorang dokter anak asal Austria pada tahun 1944. Meskipun baru diteliti dan diakui secara luas oleh para ahli pada dekade 1980-an. Syndrom asperger dibedakan dengan gejala autism lainnya dilihat dari kemampuan linguistic dan kognitif para penderitanya yang relatif tidak mengalami penurunan, bahkan dengan IQ yang relatif tinggi atau rata-rata (Ini berarti sebagian besar penderita syndrome asperger bisa hidup secara mandiri, tidak seperti autism lainnya).Syndrome asperger juga bukanlah sebuah penyakit mental ${ }^{18}$. Sindrom Asperger pertama kali dideskripsikan oleh dokter anak di Wina, Hans Asperger pada tahun 1940-an. Hans mengamati autism, seperti perilaku dan kesulitan dengan keterampilan dan komunikasi sosial dalam anak laki-laki yang memiliki pengembangan kecerdasan dan bahasa yang normal.

Banyak profesional merasa sindrom Asperger hanyalah bentuk yang lebih ringan dari autis dan menggambarkan orang-orang tersebut dengan istilah highfunctioning autism. Uta Frith, seorang professor di Lembaga Ilmu Saraf Kognitif (University College London) dan editor dari buku \'Autism and Asperger Syndrome \', menjelaskan individu dengan Asperger "memiliki sejumput autisme". Pada tahun 1994, Asosiasi Psikiatri Amerika memasukkan sindrom Asperger ke dalam Diagnostic and Statistical Manual of Mental Disorders (DSM-IV), sebagai gangguan yang terpisah dari autisme. Keduanya terdaftar sebagai subkategori dalam diagnosis "Gangguan Perkembangan Pervasif". Namun banyak profesional menganggap bahwa sindrom

${ }_{18}$ Christopher Sunu, Unlocking Autism,(Yogyakarta: Lintang Terbit), 2012, 771. 
Asperger merupakan bentuk yang tidak terlalu parah dari autism. Dan akhirnya, dalam DSM-5 (yang dikeluarkan pada tahun 2013) disebutkan bahwa gangguan autis, Asperger dan gangguan perkembangan pervasif lainnya berada dalam payung diagnosis Autism Spectrum Disorder (ASD). ${ }^{19}$

\section{HASIL DAN PEMBAHASAN}

penting untuk memperoleh informasi yang diperlukan untuk memulai pendekatan pada anak. ${ }^{20}$ Sebelum memulai pelajaran, guru harus mengetahui semua informasi yang terkait dengan anak berpengidap sindrom asperger (autisme) agar terasa lebih dekat dan mengetahui kebiasaan-kebiasaan yang mereka lakukan, khususnya yang membuat mereka merasa nyaman. Setelah sudah ketemu rasa nyaman tersebut, ini akan berdampak positif untuk peningkatan efektifitas pembelajaran khususnya PAI yang membutuhkan sentuhan-sentuhan yang mendalam.

Tidak mudah menjadi pendidik siswa dengan pengidap autisme. Perlu kesabaran yang sangat ekstra disertai kasih sayang yang penuh, karena mereka juga sama-sama makhluk ciptaan Allah. Namun dengan pemahaman dan pembelajaran yang baik, pendidik dapat membuat anak autisme dapat sama-sama berkembang dan hidup secara lebih baik. ${ }^{21}$

Pada Autisme adalah gangguan perkembangan yang bersifat kompleks dan berawal pada masa kanak-kanak. Kondisi ini memengaruhi perilaku dan kemampuan anak dalam berkomunikasi, baik lisan maupun non-lisan, serta cara anak bersosialisasi. Sasaran utama penanganan autisme adalah untuk meningkatkan kemampuan anak dalam berkomunikasi, baik lisan maupun non-lisan, serta cara anak bersosialisasi. Sasaran utama penanganan autisme adalah untuk meningkatkan kemampuan anak secara menyeluruh. ${ }^{22}$

Deteksi dini untuk anak autis sangat penting dalam menyikapi kondisi seorang anak. Utamanya untuk masa tumbuh kembang si buah hati. Peran orang tua dan guru dianggap mengambil peran penting untuk mengetahui betul kondisi perkembangan bahasa, sosial, maupun perilaku emosi sang anak. Setelah kondisi anak terdeteksi autisme, para orang tua dan guru harus berkonsultasi dengan ahli atau pakar yang mampu memberikan diagnosa yang tepat. Kelak, hasil diagnosa inilah yang akan menentukan bagaimana terapi, stimulus, ataupun siklus terstruktur yang tepat untuk bisa diberikan pada anak berkebutuhan khusus. Stimulus tersebut akan melihat atau

${ }^{19}$ Saeful Imam,"Sindrom Asperger" https://nationalgeographic.grid.id/. Diakses pada 3 Mei 2016.

${ }^{20}$ Greenspan, Stanley I. The Child with Special Needs (USA: Perseus Books, 1998).

${ }^{21}$ Wawancara dengan Pak Muhammad Hafid, selaku pengajar PAI di Sekolah khusus Al-Ihsan 01 Tangerang Selatan 11 Oktober 2019.

${ }_{22}$ Christopher Sunu, Unlocking Autism (Yogjakarta: Lintang Terbit, 2012), 178. 
memproyeksi kecenderungan gejala yang ditimbulkan oleh anak ketika berinteraksi. Stimulasi ini juga untuk menentukan dan mengembangkan cara interaksi sosial pada anak autis. Dalam kasus anak berkebutuhan khusus, terdapat anak yang bahkan kesulitan atau sama sekali tidak mengeluarkan bahasa dari mulutnya. Biasanya di situasi ini mereka hanya bergumam. Dalam hal ini, peran lingkungan keluarga dinilai amat penting karena bahasa pertama kali dipelajari anak melalui lingkungan keluarga. Oleh sebab itu, peran orang tua atau keluarga merupakan dasar pertama untuk mengembangkan kemampuan anak autis terutama dalam melatih mereka untuk mampu berkomunikasi. Struktur-truktur stimulasi tersebut bisa berupa pelatihan dengan pola meniru. Tentu kita bisa tahu anak akan sangat senang meniru. ${ }^{23}$

Namun, dalam konsep meniru perlu diperhatikan juga agar anak meniru hal-hal positif dari lingkungan keluarganya. Nanti ini berkaitan juga dengan pengendalian melatih emosi dan perilaku anak. Selain menstimulasi dengan meniru, pemberian reward atau hadiah berupa makanan atau mainan kesukaan pun menurut beliau bisa menjadi metode menstimulasi anak berkebutuhan khusus ini untuk mengontrol perilakunya. Reward ini untuk sekadar terapi dan menstimulus anak agar bisa patuh dan mengerti jika perilakunya baik maka ia bisa mendapatkan feedback yang baik juga yaitu hadiah, terapi terstruktur dan sistematis ini pun bisa dilatih pada anak berkebutuhan khusus jika terjun di lingkungan pendidikan. Dalam lingkungan pendidikan, anak berkebutuhan khusus seperti autisme ini sebetulnya bisa berada di lingkungan sekolah reguler yang inklusif jika stimulasi awal dari keluarga dan terapis telah terserap dengan baik. Jika mereka sudah diterapi, mengerti, dan patuh mereka bisa terjun ke sekolah tapi sekolahnya yang mengerti anak berkebutuhan khusus (inklusif) sebab mereka masih tetap memerlukan pendampingan. Kecerdasan Intelektual Penderita Autisme Cukup Tinggi Bukan tanpa alasan terapi tersebut harus diberikan. Sebab, dokter terapis menyebutkan anak autis, terutama autisme mental memiliki range IQ yang cenderung luas sama seperti anak pada umumnya. Hanya saja perbedaan yang dimimiliki oleh anak autisme mental ini adalah keterbatasan komunikasi dan interaksi sosial saja. "IQ mereka (penderita autisme mental-red) ini sebenarnya ada yang rata-rata, tinggi bahkan memiliki kecenderungan atau kemampuan intelektual tetentu seperti IT, seni atau lainnya. Jadi sayang jika mereka memiliki IQ yang baik tapi harus di tempatkan di SLB. Oleh karena itu menambahkan lembaga pendidikan harus memberikan penerimaan yang baik terhadap potensi anak berkebutuhan khusus tersebut. Memang anak autis harus diajarkan sepanjang hayat tapi bagi mereka yang berpotensi dan memiliki peluang sudah selayaknya diberikan penerimaan dengan baik, terkhusus lembaga pendidikan sekolah regular. ${ }^{24}$

${ }^{23}$ Christopher Sunu, Unlocking Autism. 178.

${ }^{24}$ Sindrom Asperger dalam Www. Dokita.co.id. Diakses tanggal 9 November 2018. 
Sangat penting bagi guru dan orang tua untuk mengumpulkan, mempelajari, dan terus memperbarui semua informasi tentang autisme. Hal ini dikarenakan gejala dan sifat autisme selalu berubah dari waktu ke waktu. Perubahan ini membuat penanganannya pun perlu disesuaikan dengan kebutuhan masing-masing penyandang autisme..$^{25}$ atau tidak sama sekali, membeo kata, intonasi bicara aneh, tampak tidak mengerti kata, serta mengerti dan menggunakan kata secara terbatas. Dari sekian banyak ciri yang tertera di atas, membeo atau ekolalia merupakan ciri utama anak autis sebagai gangguan kualitatif dalam perkembangan komunikasi. Contoh dari ekolalia adalah seorang anak autis bisa secara terus menerus mengulang satu kata, kalimat atau nyanyian tanpa dimengerti artinya. Ciri ekolalia ini biasanya dimiliki penyandang autis muda dengan kemampuan verbal. Akan tetapi, ciri ekolalia bukanlah satu ciri yang penting karena dalam perkembangan anak umum juga terdapat fase di mana anak mulai bisa meniru dan selalu menulang kata yang baru diketahuinya. Untuk membedakannya dengan anak autis, orang tua dapat mengetahuinya dengan cara apakah anak menyertai arti kata yang didengar atau diucapkannya.

Selain ekolalia, ciri lain yang menonjol dan perlu diperhatikan lingkungan anak autis adalah anak autis memiliki keterbatasan memahami atau menggunakan kata dan hanya secara harfiah. Dengan kata lain, anak autis memiliki keterbatasan memahami kiasan atau sindiran. Karena keterbatasan inilah orang tua, guru, dan lingkungan anak autis hendaknya menggunakan kalimat yang to the poin atau langsung pada apa yang dimaksud. Ketika berbicara dengan anak autis, hindari kalimat yang berbelit atau penuh dengan kiasan. Karena anak akan kebingungan mengartikan kalimat yang didengarnya.

Jika dalam suatu komunikasi biasanya dilakukan interaksi dua arah, pada komunikasi anak autis biasanya dilakukan hanya satu arah. Misalnya, dua orang berkomunikasi seperti biasa untuk dapat saling memberi dan menerima informasi, tetapi anak autis berkomunikasi hanya untuk menerima informasi atau memberi informasi. Untuk itu komunukasi anak autis bukanlah hubungan dua arah, melainkan satu arah.

Selain mengetahui beberapa ciri penting di atas, orang tua hendaknya memiliki pengetahuan perkembangan bahasa dan komunikasi yang dimiliki anak pada umumnya. Pengetahuan ini penting karena orang tua bisa membandingkan langsung perkembangan bahasa dan komunikasi yang dimiliki anak.

Beberapa ciri komunikasi anak autis di atas tidak melulu harus dimiliki oleh satu orang anak autis. Semua ciri ini hanya bersikap menyeluruh atau komperehenshif. Mungkin saja seorang anak autis memiliki separuh ciri di atas, atau mungkin hanya

25 Wawancara dengan Pak Yayat Hidayat selaku guru kelas SD di Sekolah khusus Al-Ihsan 01 Tangerang Selatan 11 Oktober 2019 
sepertiganya. Kendati demikian, banyak atau tidaknya ciri yang ada dalam diri anak autis bukanlah penghalang orang tua untuk melakukan penanganan terbaik.

\section{KESIMPULAN}

Dibandingkan dengan pendekatan lain, pendekatan Floor Time sangat memberikan perhatian yang khusus dan mendalam, serta sangat mendukung efektifitas pembelajaran PAI bagi guru dan anak autis. Floor Time sangat membantu komunikasi dua arah antara guru dan anak autis yang mana sangat dibutuhkan oleh anak autis agar efektif dalam pembelajaran khususnya PAI, Dibandingkan dengan pendekatan lain Floor Time lebih memberikan dorongan untuk mengungkapkan dan menggunakan perasaan dan ide-ide. Dan hal ini membuat anak autis lebih percaya diri. Floor Time sangat membantu anak autis berpikir yang logis. 


\section{DAFTAR PUSTAKA}

Alter, Mark D. Autism And Increased Paternal Age Related Changes In Global Levels Of Expession Regulation. Public Library of Science One Jurnal. 2013

American Psychiatric Association, Diagnostik and Statistical Manual of Mental Disorders, Washington DC.: American Psychiatric Association Publisher, 2013.

Amri, Sofan. Pengembangan \& Model Pembelajaran dalam Kurikulum 2013. Jakarta: Prestasi Pustakaraya, 2013.

Andayani, Dian dan Majid Abdul, Pendidikan Agama Islam Berbasis Kompetensi Konsep dan Implementasi Kurikulum, Bandung: PT.Remaja Rosdakarya. 2004.

Arief, Armai, Pengantar Ilmu dan Metodologi Pendidikan Islam. Jakarta: Ciputat Press. 2002.

Anaroga, Pandji. Psikologi Kepemimpinan. Jakarta: Rineka Cipta, 2004.

Anderson, E.A. "Measuring Service Quality at A University Health Clinic." Intenational Journal of Healt Care Quality Assurance, 1995.

Antonio, Muhammad Syafii. Muhammad Saw: The Super Leader Super Manager. Jakarta: ProLM Centre \& Tazkia Publishing, 2009.

Arifin, Imron. Kepemimpinan Kyai: Studi Kasus Pondok Pesantren Tebu Ireng. Malang: Kalimasada Press, 1993.

Arifin, Barnawi dan Mohammad. Kinerja Guru Profesional. Jakarta: Ar-Ruzz Media, 2012.

Arifin, Samsul. Pendidikan Agama Islam, Yogyakarta: Deepublish, 2014.

Arikunto. Suharsini Prosedur penelitian: suatu pendekatan praktik, Jakarta: Rineka Cipta, 2010

Arsyad, Soeratno dan Lincolin. Metodologi Penelitian untuk Ekonomi dan Bisnis, Yokyakrta: UPP AMP YKPN, 2003.

Athiyaman, Adee. "Linking student satisfaction and service quality perceptions: the case of university education." European Journal of Marketing. t.p, t.th.

Aththabari, Abu Ja'far Muhammad Bin Jarir. Tafsisr Ath-Thabari, Penerjemah Akhmad Afandi , Jakarta: Pustaka Azzam, 2008.

Atmodiwirio, dan Totosiswanto. Kepemimpinan Kepala Sekolah. Semarang: CV. Adi Waskita, 1991.

Atmodiwirio. Soebagio Manajemen Pendidikan Indonesia, Jakarta: PT. Ardadizya Jaya, 2000.

Azan, Khairul. "Mutu Layanan Akademik Studi tentang Pengaruh Pemanfaatan Fasilitas Belajar dan Kinerja Staf Program Studi terhadap Mutu Layanan Akademik Program Studi di Sekolah Pascasarjana Universitas Pendidikan Indonesia." Tesis. Bandung: Universitas Pendidikan Indonesia, 2004. 
Azizy, A.Qadri, A. Pendidikan Agama Untuk Membangun Etika Sosial :Mendidik Anak Sukses Masa Depan Pandaidan Bermanfaat).Semarang: Aneka Ilmu. 2003.

Bakry, Oemar. Tafsir Rahmat, Jakarta: PT. Mutiara, 1983.

Basyarahil, Thariq Muhammad A-Suwaidan dan Faisal Umar. Shina'atul Qa'id: Melahirkan Pemimpin Masa Depan, Terj. M. Habiburrahim, Jakarta: Gema Insani, 2005.

Bayuaji, Rizal Bima. Pengaruh Pelatihan. “Disiplin Kerja Dan Gaya Kepemimpinan Terhadap Produktivitas Kerja Karyawan Studi Pada Otoritas Jasa Keuangan Regional 3 Surabaya." Skripsi, Surabaya: Univesitas Dipenogoro, 2015.

Bisri, A. Mustofa. Percik-percik Keteladanan Kyai Hamid Ahmad Pasuruan. Rembang: Lembaga Informasi dan Studi Islam (L'Islam) Yayasan Ma"chad as -Salafiyah, 2003.

Bober, J. Marcie, "The Challenges of Instructional Accountability." Tech trends Journal, Vol. 48 no.4, 2004.

Budiyono, Amirullah Haris. Pengantar Manajemen. Yogyakarta: Graham Ilmu, 2004.

Damsyiqi, Abi Fada' Al-Hafidz Ibnu Katsir. Tafsir Al-Qur'an Al-Adzim. Beirut: alMaktabah al-Ilmiyah, t.th.

Danuatmaja, Bonny,. Terapi Anak autis di Rumah. Jakarta: Puspa Swara. 2003.

Darajat, Zakiah., et al. Ilmu Pendiidkan Islam. Jakarta: Bumi Aksara, 2014.

Darmawan, Deni. Metode Penelitian Kuantitatif. Bandung : PT. Remaja Rosdakarya, 2013.

Daryanto, H.M. Administrasi Pendidikan. Cet. 6, Jakarta: Renika Cipta, 2010.

Departemen Agama Republik Indonesia. Al-quran dan Tafsirnya. Yogyakarta: PT Dana Bhakti Wakaf, 1995.

Departemen Pendidikan dan Kebudayaan Republik Indonesia, Undang-undang Republik Indonesia, No. 2 Tahun 1989 tentang Sistem Pendidikan Nasional dan Penjelasanya. Jakarta: t.p, 1989.

Dharmmesta, Basu Swastha, dan Hani Handoko, Manajemen Pemasaran: Analisis Perilaku Konsumen. Yogyakarta: BPFE, 2013.

Dhofier, Zamakhsyari, Tradisi Pesantren, Studi Pandangan Hidup Kyai Dan Visinya Mengenai Masa Depan Indonesia, Jakarta : LP3ES, 2011.

Djojonegoro, Wardiman. Pelaksanaan Pedoman Disiplin Nasional dan Tata Tertib sekolah, Jakarta: CV. Mini Jaya Abadi, 1998.

Dunggio, Mardjan. "Semangat Dan Disiplin Kerja Terhadap Produktivitas Kerja Karyawan." Jurnal EMBA, Vol. 1 No. 4, 2013.

E, Watkins. Teacher Performance Evaluation: Building Tomorrow Today. Mississippi: Jackson Public School, 2004.

E.T, Russeffendi. Dasar-dasar Penelitian Pendidilkan dan Bidang Non Eksakta lainnya. Bandung: t.p, 1998. 
Ekhsan, Moch. Kiai Kelana, Biografi Kiai Muchith Muzadi. Yogyakarta: LKIS Yogyakarta, 2000.

Elliot, K. M.Healy, "Key factors influencing student satisfaction related to recruitment and retention." Journal of Marketing for Higher Education, 2001.

Engkoswara \& Aan Komariah, Aministrasi Pendidikan, Bandung, Alfabeta, 2012.

F, Tjiptono. Pemasaran Jasa. Malang: Banyumedia Publishing. 2005.

Fatah, Nanang. Landasan Manajemen Pendidikan. Cet. ke 3, Bandung: PT Remaja Rosdakarya, 2003.

Fikri, Sirhan, Wahyu Wiyani, et. al. "Pengaruh Kualitas Pelayanan Terhadap Kepuasan dan Loyalitas Mahasiswa." Jurnal. Malang: Universitas Merdeka Malang,t. th.

Fred N., Kerlinger. Asas-asas Penelitian Behavioral Edisi Ketiga, diterjemahkan oleh Landung R. Simatupang. Yogyakarta: Gajah Mada University Press, 1990.

Ghozali, Imam. Aplikasi Analisis Multivariate dengan Program IBM SPSS 19. Semarang: Badan Penerbit Universitas Diponegoro, 2011.

Greenspan, Stanley I. The Child with Special Needs, USA: Perseus Books, 1998.

Hadi, Sutrisno. Metodologi Research, Yogyakarta: Andi Offset, 1990.

Saihu, "Komunikasi Pendidik Terhadap Anak Berkebutuhan Khusus di Sekolah Khusus Asy-Syifa Larangan", Andragogi: Jurnal Pendidikan Islam, VOL 1, No. 3 (2019): 418-440. 